\title{
Aerosol flux measurements above a mixed forest at Borden, Ontario
}

\author{
M. Gordon, R. M. Staebler, J. Liggio, A. Vlasenko, S.-M. Li, and K. Hayden \\ Science and Technology Branch, Environment Canada, Toronto, Canada \\ Received: 16 July 2010 - Published in Atmos. Chem. Phys. Discuss.: 1 October 2010 \\ Revised: 4 July 2011 - Accepted: 4 July 2011 - Published: 18 July 2011
}

\begin{abstract}
Aerosol fluxes were measured above a mixed forest by Eddy Covariance (EC) with a Fast Mobility Particle Sizer (FMPS) at the Borden Forest Research Station in Ontario, Canada between 13 July and 12 August 2009. Chemically speciated flux measurements were made at a height of $29 \mathrm{~m}$ at the same location between 19 July and $2 \mathrm{Au}-$ gust, 2006 using a Quadrupole Aerosol Mass Spectrometer (Q-AMS). The Q-AMS measured an average sulphate deposition velocity of $0.3 \mathrm{~mm} \mathrm{~s}^{-1}$ and an average nitrate deposition velocity of $4.8 \mathrm{~mm} \mathrm{~s}^{-1}$. The FMPS, mounted at a height of $33 \mathrm{~m}$ (approximately $10 \mathrm{~m}$ above the canopy top) and housed in a temperature controlled enclosure, measured sizeresolved particle concentrations from 3 to $410 \mathrm{~nm}$ diameter at a rate of $1 \mathrm{~Hz}$. For the size range $18<D<452 \mathrm{~nm}, 60 \%$ of fluxes were upward. The exchange velocity was between -0.5 and $2.0 \mathrm{~mm} \mathrm{~s}^{-1}$, with median values near $0.5 \mathrm{~mm} \mathrm{~s}^{-1}$ for all sizes between 22 and $310 \mathrm{~nm}$. The size distribution of the apparent production rate of particles at $33 \mathrm{~m}$ peaked at a diameter of $75 \mathrm{~nm}$. Results indicate a decoupling of the above and below canopy spaces, whereby particles are stored in the canopy space at night, and are then diluted with cleaner air above during the day.
\end{abstract}

\section{Introduction}

Atmospheric aerosol particles are generated by both anthropogenic and natural sources and through chemical and physical processes in the atmosphere. The sizes of airborne aerosols range from a few nanometers to tens of micrometers. The dynamics of atmospheric aerosols is highly complex, involving particle formation, growth, and surface exchange processes. Effects of aerosols include direct and indirect climate forcing (Forster et al., 2007) through the absorption and scattering of incoming solar radiation and the forma-

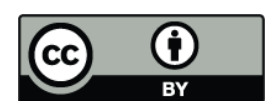

Correspondence to: $\mathrm{M}$. Gordon (mark.gordon@ec.gc.ca) tion of clouds by condensation nuclei activation; reduction of visibility (Malm, 2003); and impairment to human health (Lippmann, 2009). Aerosols are carriers of compounds containing nitrogen $(\mathrm{N})$, sulphur $(\mathrm{S})$, and other elements over large distances. The eventual deposition of sulphate $\left(\mathrm{SO}_{4}^{2-}\right)$ and nitrate $\left(\mathrm{NO}_{3}^{-}\right)$aerosols can lead to acidification of the environment and the deposition of nitrate can also lead to eutrophication, especially in sensitive ecosystems (Spranger et al., 2004).

Dry deposition of aerosols to the surface is primarily a function of particle size, boundary layer conditions (turbulence intensity), and collecting properties of the surface. The theoretically predicted deposition rate is lowest for particle sizes between $100 \mathrm{~nm}$ and $2 \mu \mathrm{m}$, with several orders of magnitude difference between different models (cf. Petroff et al., 2008). In a review of particle atmosphere-surface exchange, Pryor et al. (2008b) conclude that: few studies have sought to quantify the dependence of flux on particle size; observations over forests do not support the theoretical minimum depositions rate manifest in models; and that more research is required to determine if dry deposition of aerosols is an important removal mechanism for ultrafine particles, especially over surfaces with high roughness, such as forests. There have been a number of studies which have measured size-resolved aerosol fluxes over forests. Forest types and locations include: mixed deciduous in eastern Tennessee (Hicks et al., 1989) and southern Indiana, USA (Pryor et al., 2009); pine in Hyytiälä, Finland (e.g. Buzorius et al., 1998; Grönholm et al., 2007); maritime pine in Les Landes, France (Lamaud et al., 1994); douglas fir in Northern Holland (Gallagher et al., 1997); spruce in Germany, at Solling (Bleyl, 2001) and near Münchberg (Held and Klemm, 2006); beech in Soro, Denmark (Pryor, 2006); and Amazonian rain forest near Manaus, Brazil (Ahlm et al., 2010). The majority of these studies measured aerosol fluxes using the eddy covariance (EC) technique with Condensational Particle Counters (CPCs), which measure the total particle number concentration over a particle size range typically between $10 \mathrm{~nm}$ and $1 \mu \mathrm{m}$. Size-resolved fluxes have been measured using

Published by Copernicus Publications on behalf of the European Geosciences Union. 
optical particle counters (Gallagher et al., 1997; Ahlm et al., 2010), relaxed Eddy Accumulation (REA) with a Differential Mobility Particle Sizer (DMPS;Grönholm et al., 2007), and EC with a Fast Mobility Particle Sizer (FMPS; Pryor et al., 2009).

Lamaud et al. (1994) found that particle deposition velocity $\left(V_{\mathrm{d}}\right)$ is related to friction velocity $\left(u_{*}\right)$ and atmospheric stability. This was also supported by the studies of Grönholm et al. (2007), Pryor (2006), Pryor et al. (2007), and Ahlm et al. $(2009,2010)$. Many studies found fluxes were often upward (negative "deposition"), with frequency ranging from near $20 \%$ (Grönholm et al., 2007) to over $40 \%$ (Pryor et al., 2008c) of the total number of flux measurements. Upward fluxes have been attributed to local emissions (Buzorious et al., 2000), particle re-suspension (Hicks et al., 1989), sources of particles within or close to the canopy top (Buzorius et al., 1998), stochastic effects in the data (Gaman et al., 2004), and entrainment during the growth of the mixing layer (Nilsson et al., 2001). Pryor et al. (2008a) analysed data from two locations with the aim of determining the source of these upward fluxes. They found a possible causal link of upward fluxes to the entrainment of particle-depleted air from the free troposphere at one location. However, no such link was apparent at the second location. They concluded that further research is warranted.

The following describes two studies which took place in a mixed coniferous and deciduous forest at the Borden Forest Flux Tower between July and August in 2006 and 2009. In the 2006 study, chemically speciated particle flux measurements were made with a Quadrupole Aerosol Mass Spectrometer (Q-AMS). In the 2009 study, size-resolved flux measurements were made with an FMPS. To the authors' knowledge, there has been only one study of size resolved fluxes over forests using EC with an FMPS (Pryor et al., 2009). The results of this study demonstrate a predominance of apparent upward fluxes at this location, allowing for further exploration of the root cause of this phenomenon.

\section{Method}

\subsection{Site description}

This study took place at the Borden Forest Research Station $\left(44^{\circ} 19^{\prime} \mathrm{N} 79^{\circ} 56^{\prime} \mathrm{W}\right)$ in Ontario, Canada. The forest is a mix of hardwood and coniferous trees from regrowth on abandoned farm land, with an age of approximately 100 years. The average canopy height was approximately $23 \mathrm{~m}$. The surrounding area, shown in Fig. 1, is generally flat within a radius of about $4 \mathrm{~km}$. The available forest fetch is about $4.3 \mathrm{~km}$ to the south, and $3 \mathrm{~km}$ to the SSW. Outside of this range was predominantly grass and cropland, with the town of Angus, Ontario less than $4 \mathrm{~km}$ to the ENE and the Canadian Forces Base Borden $5 \mathrm{~km}$ to the SE.

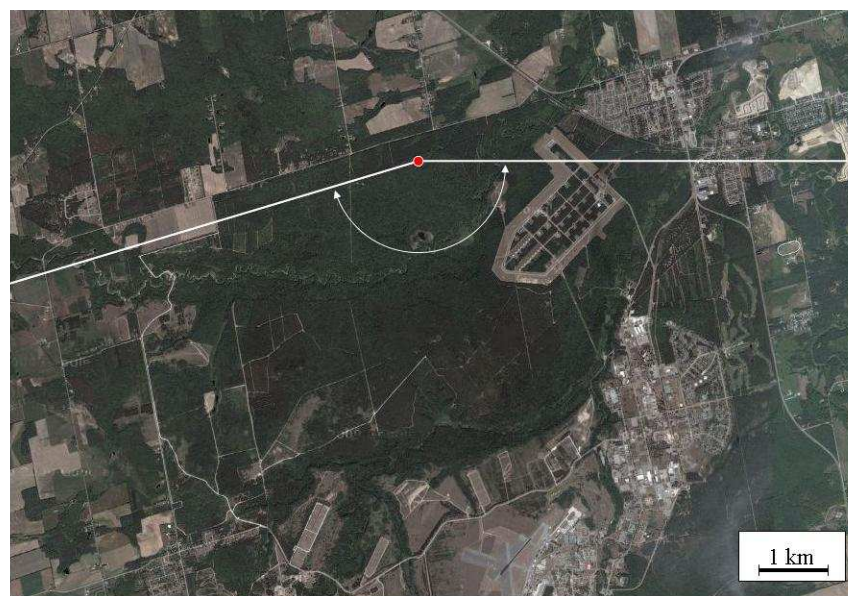

Fig. 1. Borden and surrounding area. Red dot shows tower location. Arrows show range of wind direction with adequate fetch. Photo reproduced from Google.com.

\subsection{Instrumentation}

Instruments were mounted on a 44-m tower. The tower supports an array of instruments for routine measurements of temperature, wind speed, humidity, and fluxes of energy, water vapour, $\mathrm{SO}_{2}$, and $\mathrm{CO}_{2}$. Details of the measurement setup can be found in Lee et al. (1999), Staebler et al. (2000), and Teklemariam et al. (2009). Herein, we present measurements (all at a $33 \mathrm{~m}$ height) of water vapour with an infrared gas analyzer (model 6262, LI-COR Inc., Lincon, Nebraska), $\mathrm{SO}_{2}$ with a pulsed fluorescence analyzer (model TECO 43C, Thermo Electron Co. Inc.), and leaf wetness with a electrical resistance plate (model 237, Campbell. Scientific, Inc., Logan, UT). A precipitation gauge was mounted $280 \mathrm{~m} \mathrm{NE}$ of the tower at a nearby pond.

During the 2009 study, an FMPS (Model 3901, TSI) was mounted above the canopy, at a height of $33 \mathrm{~m}$, and was operational from 13 July to 9 August, 2009 (Day of year, DOY 194 to 221). The FMPS is based on electrical aerosol spectrometer technology (Tammet et al., 2002) and measures particle concentration at a maximum rate of $1 \mathrm{~Hz}$ in 32 size bins with a manufacturer specified range of 6 to $560 \mathrm{~nm}$ electrical mobility diameter. The FMPS at $33 \mathrm{~m}$ was housed in a temperature-controlled enclosure, to reduce instrument variability due to temperature changes. The temperature within the enclosure was maintained at $20 \pm 3{ }^{\circ} \mathrm{C}$ throughout the study, resulting in a diurnal variation of the instrument sheath air temperature of $<1^{\circ} \mathrm{C}$. The FMPS sampled air through a $4-\mathrm{m}, 6.35 \mathrm{~mm}(0.25 \mathrm{inch})$ outer diameter, stainless steel tube, with a residence time of approximately $0.3 \mathrm{~s}$ (Reynolds number, $R e \approx 4000$ ). A sonic anemometer (Applied Technologies, Inc., ATI) for EC measurements was mounted near the sample inlet. A second FMPS sampled below the canopy, at a height of $2 \mathrm{~m}$ a.g.l. and was operational from 13 to 25 July 2009. 
Both FMPS instruments were size-calibrated prior to the field study with a reference Condensational Particle Counter (CPC, model 3775, TSI) using both polystyrene latex spheres (Duke Scientific) of known size and $\mathrm{NH}_{4} \mathrm{NO}_{3}$ particles. The size calibration was done with particles in the 30 to $450 \mathrm{~nm}$ range with and without size selection using a Scanning Mobility Particle Sizer (SMPS, TSI). A power-law, least-squares fit gives a relation between the FMPS specified diameter ( $\left.D_{\text {FMPS }}\right)$ and the actual diameter of $D=0.29 D_{\text {FMPS }}^{1.31}(\mathrm{~nm})$ with $r^{2}=0.984$. This gives an actual FMPS size range of $3<D<1060 \mathrm{~nm}$. However, since the calibration was performed with 30 to $450 \mathrm{~nm}$ diameter particles only, size estimations of the smallest 9 bins $\left(6<D_{\mathrm{FMPS}}<20 \mathrm{~nm}\right)$ and the largest 5 bins $\left(294<D_{\text {FMPS }}<523 \mathrm{~nm}\right)$ were not used for the flux analysis.

During the 2006 study, a Quadrupole Aerosol Mass Spectrometer (Q-AMS) was mounted on the tower at a height of $29 \mathrm{~m}$ between 19 July and 2 August 2006 (DOY 200 to 214). The Q-AMS, described in detail in Jimenez et al. (2003), measures the non-refractory components of aerosols of 40 to $700 \mathrm{~nm}$ vacuum aerodynamic diameter $\left(D_{\mathrm{va}}\right)$. The Q-AMS was alternated between mass spectrum (MS) and jump mass spectrum (JMS) modes every $30 \mathrm{~min}$. In the MS mode, the mass to charge $(\mathrm{m} / \mathrm{z})$ ratios of 1 to 300 were scanned every $300 \mathrm{~ms}$ and average spectra were output every $15 \mathrm{~min}$. In the JMS mode (Crosier et al., 2007; Nemitz et al., 2008), 10 specific $m / z$ values were recorded at a frequency of $10 \mathrm{~Hz}$, which was post-processed to $1 \mathrm{~Hz}$ to reduce measurement noise. This JMS flux mode differs from the standard AMS-JMS mode in that the instrument beam is kept open for $28 \mathrm{~min}$. In the following analysis we concern ourselves with $\mathrm{m} / \mathrm{z}=30$ and 46 (particle $\mathrm{NO}_{3}^{-}$) and $m / z=48$ and 64 (particle $\mathrm{SO}_{4}^{2-}$ ). The Q-AMS sampled air through a 4-m, $6.35 \mathrm{~mm}(0.25 \mathrm{inch})$ outer diameter, stainless steel tube, with a residence time less than $0.4 \mathrm{~s}$. A sonic anemometer (ATI) was mounted near the sample inlet, and EC was used to determine mass fluxes, $F_{m}$. Details of how EC measurements are made using a Q-AMS can be found in Nemitz et al. (2008). In addition to the standard tower micrometeorological instrumentation discussed above, a fast-response $\mathrm{NH}_{3} / \mathrm{NO}_{\mathrm{y}}$ detector (CLD $88 \mathrm{CYpr}$, Eco-Physics AG, Switzerland) was used to measure ammonia concentration at $32 \mathrm{~m}$ and an SMPS measured particle size distributions at $33 \mathrm{~m}$ over a size range of 14 to $523 \mathrm{~nm}$.

\section{Data analysis}

Conservation of mass for the aerosol particle concentration $C$ gives (e.g. Businger, 1986)

$$
\frac{\partial C}{\partial t}+\frac{\partial}{\partial x_{i}}\left(u_{i} C\right)+\frac{\partial}{\partial z}\left(V_{\mathrm{g}} C\right)=D_{M} \frac{\partial^{2}}{\partial x_{i}^{2}} C+S
$$

where $D_{M}$ is the particle diffusion coefficient (due to Brownian motion), $V_{\mathrm{g}}$ is the gravitational settling velocity, $S$ is a source or sink term, and the subscript $i$ is a summation index such that $\left(x_{1}, x_{2}, x_{3}\right)=(x, y, z)$ and $\left(u_{1}, u_{2}, u_{3}\right)=(u, v, w)$. For small particles $(<1 \mu \mathrm{m})$ it can be assumed that $V_{\mathrm{g}} \approx 0$ and that the molecular diffusion term is small relative to the other terms. Assuming horizontal homogeneity, incompressible flow, and steady state, Reynolds decomposition and integration in $z$ to the measurement height, $z_{r}$, gives

$$
\int_{0}^{z_{r}} \frac{\partial \bar{C}}{\partial t} d z+\overline{w^{\prime} C^{\prime}}\left(z_{r}\right)=\int_{0}^{z_{r}} \bar{S} d z
$$

where the overbar and prime denote mean and fluctuating terms. For simplicity, Eq. (2) is rewritten as

$$
F_{\text {Stg }}+F=S_{T}
$$

The term $S_{T}$ is the net sum of sources and sinks below $z_{r}$ per unit area, and $F_{\text {Stg }}$ is the storage flux, so called because a positive concentration change rate below the measurement height is equivalent to a "storage" or build-up of particles in the control volume. Conversely, a negative $F_{\text {Stg }}$ is equivalent to a dilution or flushing of particles from the control volume. Since $F_{\mathrm{Stg}} \approx z_{r}(\bar{C}(t+\Delta t)-\bar{C}(t)) / \Delta t$, the storage flux will become negligible if the averaging time, $\Delta t$, is large (many days to weeks), especially if the concentration varies periodically and the integration time is an integer multiple of the period. From Eq. (3), this gives $\langle F\rangle=\left\langle S_{T}\right\rangle$, where \langle\rangle denotes a long-term average. Hence, the average flux will be equal to the average particle creation or removal rate per unit area.

An exchange velocity is defined as $V_{\mathrm{e}}=F / \bar{C}=-V_{\mathrm{d}}$, where $V_{\mathrm{d}}$ is a deposition velocity (with the negative sign added since flux is positive upwards and deposition is positive in a downward direction). For the following analysis, concentrations and fluxes were calculated in 30-min intervals. The concentration data were also filtered for low frequencies by linear de-trending of each 30-min interval.

\subsection{Corrections and filtering}

In the 2009 study, a total of $n=736$ intervals were measured. Only data with wind direction in the range $90^{\circ}$ to $255^{\circ}$ (Teklemariam et al., 2009) were used since other wind directions represent insufficient homogeneous fetch for flux measurements, as is illustrated in Fig. 1. EC measurements with friction velocity, $u_{*}<0.2 \mathrm{~m} \mathrm{~s}^{-1}$ were also removed as they are considered unreliable due to low turbulent mixing (Teklemariam et al., 2009). After filtering for wind direction and friction velocity, the data comprise $n=233$ intervals (a removal of $68 \%$ ). Unless noted otherwise, only these 233 intervals were used in all FMPS flux measurement analysis.

Each 30-min average wind velocity was used to rotate the anemometer measurements following Wilczak et al. (2001), with one rotation around the z-axis to give $\bar{v}=0$, and a second rotation around the $\mathrm{y}$-axis to give $\bar{w}=0$. Fluxes were corrected for variation in density due to the flux of water vapour following Webb et al. (1980). This correction was never more than $1 \%$. No correction was made for variation 
in density due to heat flux, as fluctuations of heat are assumed to be dissipated in the 4-m inlet tube (Rannik et al., 1997).

Fluxes were also corrected for the attenuation of the signal carried by frequencies $>1 \mathrm{~Hz}$ due to the sampling frequency of the instrument, following Horst (1997). This frequency response correction is based on stability $z / L$, where $z$ is the measurement height and $L$ is the Monin-Obukhov length. The average corrections can be represented as the average ratio of corrected to uncorrected fluxes $\left(\left\langle F / F_{0}\right\rangle\right)$ or as the ratio of the average corrected flux to the average uncorrected flux $\left(\langle F\rangle /\left\langle F_{0}\right\rangle\right)$, where $F$ and $F_{0}$ are the corrected and uncorrected fluxes, respectively. This gives an average increase of $\left\langle F / F_{0}\right\rangle=9.8 \%$, and a total increase of $\langle F\rangle /\left\langle F_{0}\right\rangle=6.2 \%$. Detailed summaries of these corrections techniques can be found in Buzorius et al. (2000), Pryor et al. (2007), and Pryor et al. (2008c).

Since the absorption or loss of water may change particle size, correlation between the saturation ratio $\left(S_{R}=\right.$ Relative Humidity/100\%) and $w$ can result in modified particle number fluxes for size-resolved measurements, when particles move into neighbouring bins due to hygroscopic growth. Two approaches to correcting this problem, which differ in their choice of particle growth formula, are outlined in Kowalski (2001) and Vong et al. (2004). We use here the model of Vong et al., which assumes a particle growth with humidity of

$$
\frac{D\left(S_{R}\right)}{D_{0}}=\left(1-S_{R}\right)^{-\gamma},
$$

where $D_{0}$ is the dry diameter and $D\left(S_{R}\right)$ is the diameter at the saturation ratio $S_{R}$. The hygroscopic growth parameter is assumed to be $\gamma=0.214$, which Swietlicki et al. (2000) suggest for "aged European air".

As shown in Vong et al. (2004), the deposition velocity correction is

$$
\Delta V_{\mathrm{d}}=\frac{-\beta \gamma \overline{w^{\prime} S_{R}^{\prime}}}{\left(1-S_{R}\right)},
$$

where $\beta$ is the power-law exponent for the particle number size distribution. For $D>300 \mathrm{~nm}$, the change in concentration with particle size can be approximated by

$d C(D) / d D \propto D^{-(\beta+1)}$.

For $D<300 \mathrm{~nm}$, Eq. (6) can be applied to the particle number size distribution for small $\Delta D$ and $\beta$ can be determined using Eq. (6) and the particle number concentrations $(C)$ of two adjacent bins. As with the Webb et al. (1980) correction, it is assumed that temperature fluctuations are dampened in the inlet. The fluxes are then corrected as

$$
F=F_{0}+\Delta V_{\mathrm{d}} \bar{C}
$$

For these data we calculate $\left\langle F / F_{0}\right\rangle=26 \%$ and $\langle F\rangle /\left\langle F_{0}\right\rangle=$ $5.8 \%$ suggesting that the effect of the deliquescence correction on individual 30-min fluxes is significant, but the effect on the complete time series is relatively small. Since the FMPS mixes sample air $\left(8 \mathrm{~L} \mathrm{~min}^{-1}\right)$ with temperature controlled sheath air $\left(40 \mathrm{~L} \mathrm{~min}^{-1}\right.$ at $\left.23^{\circ} \mathrm{C}\right)$, the extent to which hydroscopic particles are dried in the FMPS sampling chamber is unknown. In the following analysis, we assume there is minimal drying and the deliquescence correction is applied to the fluxes. However, the uncertainty in the flux measurements due to this unknown is equal to the correction, which is smaller than $6 \%$ on average.

The 2006 Q-AMS flux measurements were filtered for wind direction and friction velocity $\left(<0.2 \mathrm{~m} \mathrm{~s}^{-1}\right)$, the anemometer measurements were rotated, and corrections for variation in density due to the flux of water vapour and attenuation of the signal carried by frequencies $>10 \mathrm{~Hz}$ were made, all following the methods described above. No deliquescence correction was necessary since the Q-AMS measures a single size range $\left(40<D_{\mathrm{va}}<700 \mathrm{~nm}\right)$, and concentrations at the upper and lower limits of the size range are relatively small. Due to technical issues with the Q-AMS, after applying corrections and filtering, there were only 92 30-min data intervals from the Q-AMS, spread over 12 days.

From herein all presentation and discussion of flux $(F)$ refers to the corrected flux measurement. It is emphasized that these apparent flux measurements may not be equal to the exchange of aerosols between the canopy and the measurement height above $\left(S_{T}\right)$, due to storage (Eq. 3) and unresolved chemical effects, which are discussed in Sect. 5.

\section{Results}

\subsection{Size-resolved measurements (2009)}

The concentrations measured by the FMPS for the entire period of the 2009 study (after filtering and corrections) are shown in Fig. 2. The peak number concentration is near $62 \mathrm{~nm}$. The solid line shows the typical FMPS noise with filtered inlet air, as specified by the manufacturer. Hence, a significant number of measurements with $D<18 \mathrm{~nm}$ and $D>452 \mathrm{~nm}$ were below the noise level of the instrument. These sizes were not used for flux analysis. As discussed in Sect. 2.2, bins below $29 \mathrm{~nm}$ and above $410 \mathrm{~nm}$ were not calibrated for size and the sizes shown in Fig. 2 are based on extrapolation of the least-squares fit.

The number of 30-min samples for each hour after filtering for wind direction and friction velocity are shown (Fig. 3a). To demonstrate the full range of the diurnal cycle, the variation of $u_{*}$ and the stability, $z_{r} / L$ are shown without filtering for friction velocity (Fig. 3b-c). The diurnal variation of the concentration, flux, and exchange velocity of the 56.8$68.6 \mathrm{~nm}$ particles are shown in Fig. 3d-f. During stable conditions $\left(z_{r} / L>0\right)$, throughout the night, turbulent fluxes and exchange velocities were generally small. During unstable $\left(z_{r} / L<0\right)$ and neutral conditions $\left(z_{r} / L \approx 0\right)$, throughout the day, the fluxes were predominantly upward. Figure $3 \mathrm{~g}$ shows 


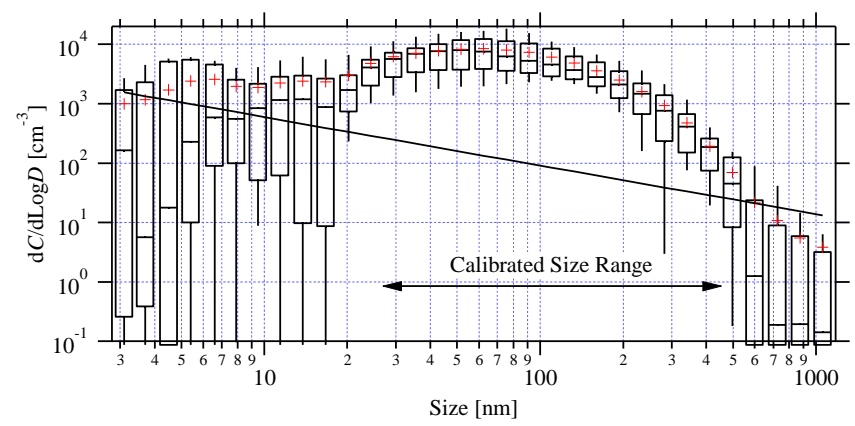

Fig. 2. Percentiles of concentration by size bin. Error lines show 10 and $90 \%$, boxes show 25 and $75 \%$, and centre-line shows medians. Average values shown as $(+)$. Solid line shows the typical FMPS noise with filtered inlet air. Sizes in the calibrated range are shown. Outside this range, sizes are based on extrapolation of the calibrated best fit.

the total exchange velocity for the range $18<D<452 \mathrm{~nm}$. The exchange velocity for the size bin with the peak upward flux $(57-69 \mathrm{~nm})$ had similar values throughout the diurnal cycle to the exchange velocity of the total measurable size range $(18<D<452 \mathrm{~nm})$.

The size resolved number concentration fluxes and exchange velocities for $D>18 \mathrm{~nm}$ are shown in Fig. 4. Fluxes for $18<D<452 \mathrm{~nm}$ were generally upward (positive medians). The fraction of upward fluxes is $60 \%$ for all sizes (i.e., $60 \%$ of the fluxes were above zero). The exchange velocity is similarly distributed for $22<D<310 \mathrm{~nm}$, with the majority of the measurements between -0.5 and $2.0 \mathrm{~mm} \mathrm{~s}^{-1}$, and median values near $0.5 \mathrm{~mm} \mathrm{~s}^{-1}$.

\subsection{Speciated measurements (2006)}

The Q-AMS measured aerosol mass during the 2006 study to be approximately $52 \%$ organics, $34 \%$ sulphate, $11 \%$ ammonium, and $3 \%$ nitrate by mass. The average $\mathrm{SO}_{4}^{2-}$ flux was $-1.3 \mathrm{ng} \mathrm{m}^{-2} \mathrm{~s}^{-1}$ and the average $\mathrm{NO}_{3}^{-}$flux was $-3.7 \mathrm{ng} \mathrm{m}^{-2} \mathrm{~s}^{-1}$ (with standard deviations of 10.1 and $6.6 \mathrm{ng} \mathrm{m}^{-2} \mathrm{~s}^{-1}$ respectively). The average $\mathrm{SO}_{4}^{2-}$ and $\mathrm{NO}_{3}^{-}$ exchange velocities were -0.3 and $-4.8 \mathrm{~mm} \mathrm{~s}^{-1}$ respectively. The difference between sulphate and nitrate fluxes are comparable to measurements by Thomas (2007) made over an oak forest in Hampshire, UK, where average fluxes of 0.5 and $-5.4 \mathrm{ng} \mathrm{m}^{-2} \mathrm{~s}^{-1}$ and exchange velocities of 0.6 and $-17.2 \mathrm{~mm} \mathrm{~s}^{-1}$ were found for $\mathrm{SO}_{4}^{2-}$ and $\mathrm{NO}_{3}^{-}$respectively.

The $\mathrm{NO}_{3}^{-}$deposition velocity followed a diurnal cycle with relatively low values through the night, a peak value between 5 and $20 \mathrm{~mm} \mathrm{~s}^{-1}$ near 12:00 UTC, and decreasing values through the day. A sample day (20 July 2006) is shown in Fig. 5a-f. Wyers and Duyzer (1997) suggested that the downward flux of $\mathrm{NO}_{3}^{-}$is due to evaporation of $\mathrm{NH}_{4} \mathrm{NO}_{3}$ when temperatures increase near the canopy relative to the

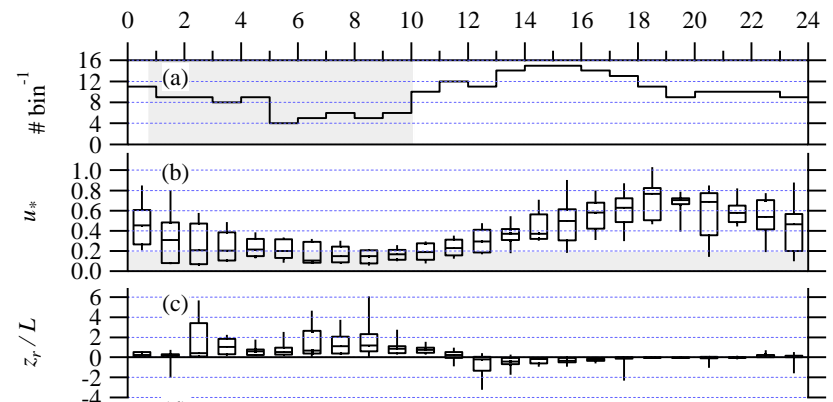

(d)
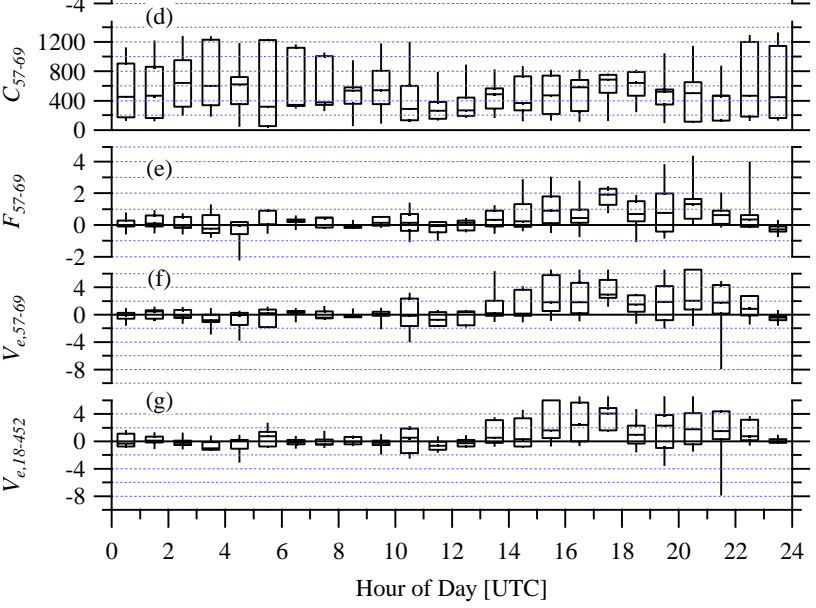

Fig. 3. Number of 30-min measurements after filtering for wind direction and friction velocity (a), percentiles (10, 25, 50, 75, and $90 \%$ ) of the diurnal variation in friction velocity, $u_{*}\left[\mathrm{~m} \mathrm{~s}^{-1}\right]$ (b), stability, $z_{r} / L$ (c), filtered concentration $C_{57-69}\left[10^{6} \mathrm{~m}^{-3}\right]$ (d), flux, $F_{57-69}\left[10^{6} \mathrm{~m}^{-2} \mathrm{~s}^{-1}\right](\mathbf{e})$, exchange velocity, $V_{e, 57-69}$ $\left[\mathrm{mm} \mathrm{s}^{-1}\right]$ (f) of the $56.8-68.6 \mathrm{~nm}$ size range, and exchange velocity, $V_{e, 18-452}\left[\mathrm{~mm} \mathrm{~s}^{-1}\right](\mathrm{g})$ of the $18.4-452 \mathrm{~nm}$ size range. Shading indicates night-time (a) and $u_{*}<0.2 \mathrm{~m} \mathrm{~s}^{-1}$ (b).

air aloft. The inset in Fig. 5f shows the temperature in the canopy $(<23 \mathrm{~m})$ increasing nearly $1.5^{\circ} \mathrm{C}$ between $10: 00$ and 10:30 UTC (lightest blue line), while the temperature above the canopy decreased approximately $1{ }^{\circ} \mathrm{C}$ (black line), which would give a relative increase in $\mathrm{NH}_{4} \mathrm{NO}_{3}$ evaporation at the canopy. However, nitrate deposition continued to increase (Fig. 5c) between 11:00 and 12:00 UTC, while temperatures were approximately equal at all heights.

\subsection{Uncertainty}

Finite sample lengths introduce an uncertainty into the measurements. The uncertainty, $\varepsilon$, depends on the choice of integration period, the variability of the flux in time, and the degree to which the flux measurement time series correlates with itself when shifted in time. The uncertainty was quantified by Lumley and Panofsky (1964) as

$$
\epsilon^{2}=\frac{2 \xi}{T}\left[\overline{\left(w^{\prime} C_{i}^{\prime}\right)^{2}}-\overline{w^{\prime} C_{i}^{\prime}}{ }^{2}\right]
$$




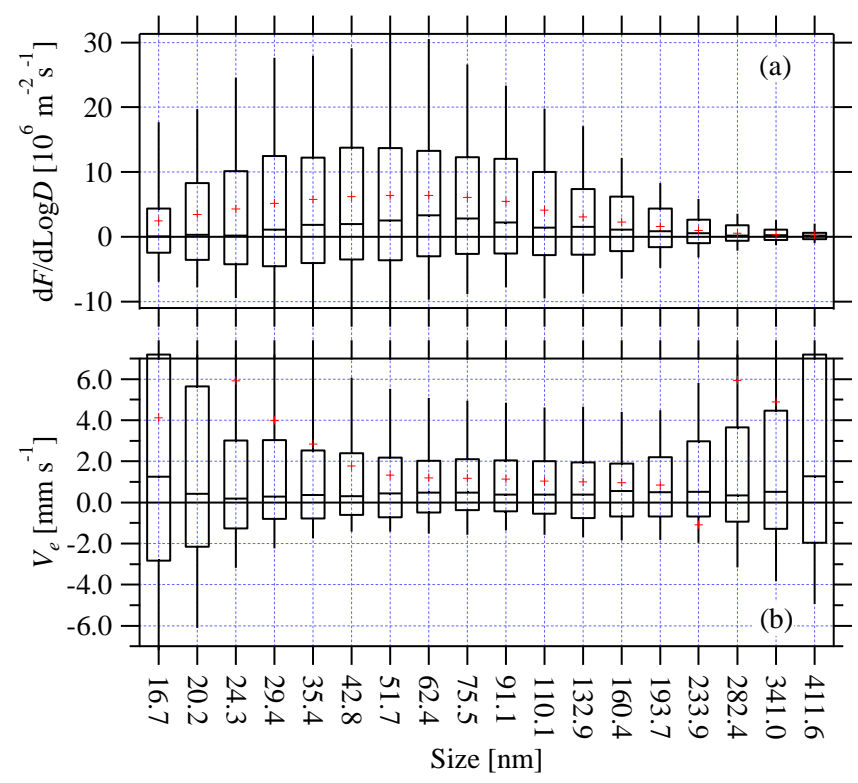

Fig. 4. Percentiles $(10,25,50,75$, and $90 \%)$ and averages $(+)$ of fluxes (a) and exchange velocities (b) by bin midpoint size $(D)$.

where $T=1800 \mathrm{~s}$ is the averaging time period, and $\xi$ is the time scale. Rannik et al. (2009) demonstrated that this uncertainty is equivalent to the standard error. Hence, we are $68 \%$ confident that the true value is within the range $F \pm \varepsilon$ and $95 \%$ confident that the true value is within the range $F \pm 2 \varepsilon$.

The time scale is calculated as

$\xi=\frac{1}{\sigma_{w C}^{2}} \int_{0}^{\infty} R_{w C}(\tau) d \tau$,

where $R_{w C}(\tau)$ is the auto-covariance, and $\sigma_{w C}^{2}=R_{w C}(0)$ is the variance of $w^{\prime} C_{i}^{\prime}$. Since a long term integration is not practical due to variation over diurnal time-scales (non-stationarity), the integral is evaluated to the first zerocrossing $\tau\left(R_{w C}=0\right)$, following Rannik et al. (2009). The error is calculated for each 30-min flux from the $62 \mathrm{~nm}$ bin $(56.8<D<68.6 \mathrm{~nm})$, since this bin has the largest fluxes. The fluxes are filtered by wind direction and friction velocity, and corrected for frequency response and deliquescence as outlined in Sect. 3.1. The distribution of the ratio of the flux $(F)$ to the error $(\varepsilon)$ is shown in Fig. 6. Approximately half the data are within $|F|<\varepsilon$, suggesting that these data are not statistically different from $F=0$ (at a $68 \%$ confidence level). At the $95 \%$ confidence interval, $21.9 \%$ of the fluxes are significantly upward $(F>2 \varepsilon)$ and $6.9 \%$ are significantly downward $(F<-2 \varepsilon)$. This demonstrates that the dominance of upward fluxes is statistically significant and not due to random uncertainties.

From the Q-AMS measurements, mass fluxes of $\mathrm{SO}_{4}^{2-}$ demonstrate no directional tendency, with $18 \%$ of the data having $F_{m}<-\varepsilon$ (from Eq. 8), and $18 \%$ having $F_{m}>\varepsilon$. Flux

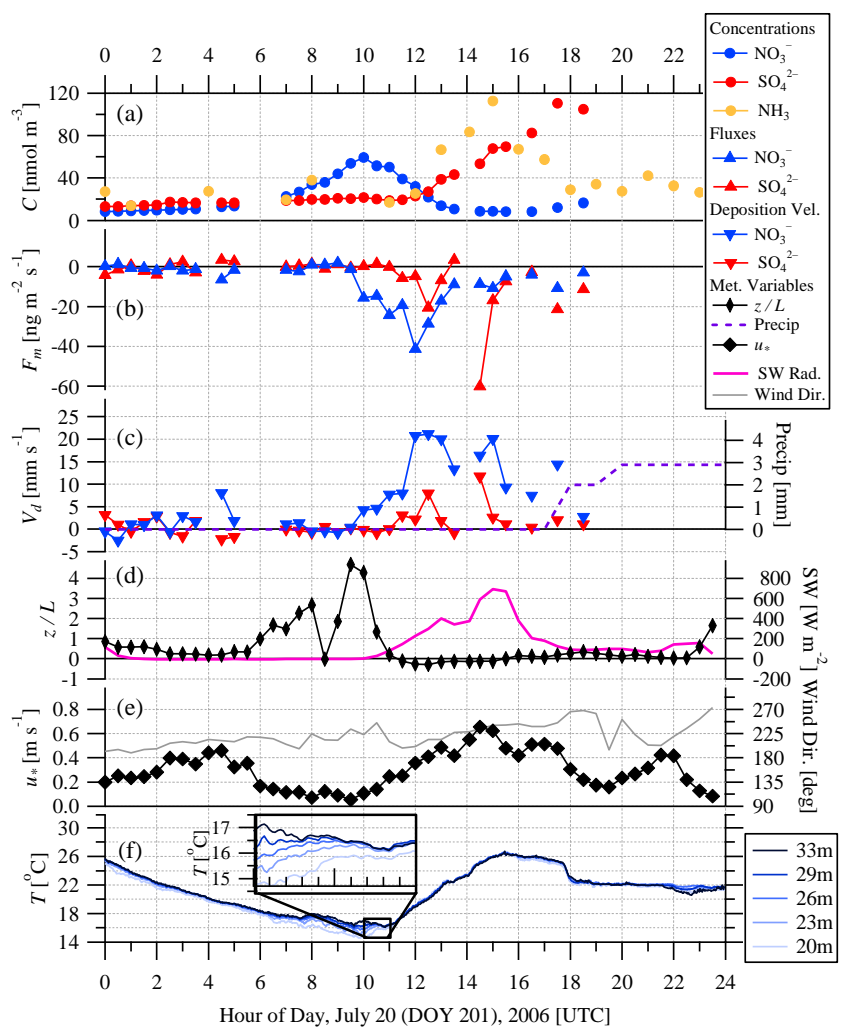

Fig. 5. $\mathrm{NO}_{3}^{-}$and $\mathrm{SO}_{4}^{2-}$ concentrations (a), mass fluxes (b), and deposition velocities (c), compared to $\mathrm{NH}_{3}$ concentration (a) and other meteorological variables (d, e) on 20 July 2006. Temperatures at various heights are shown (f). Inset in (f) shows temperatures from 10:00 to 11:00 UTC.

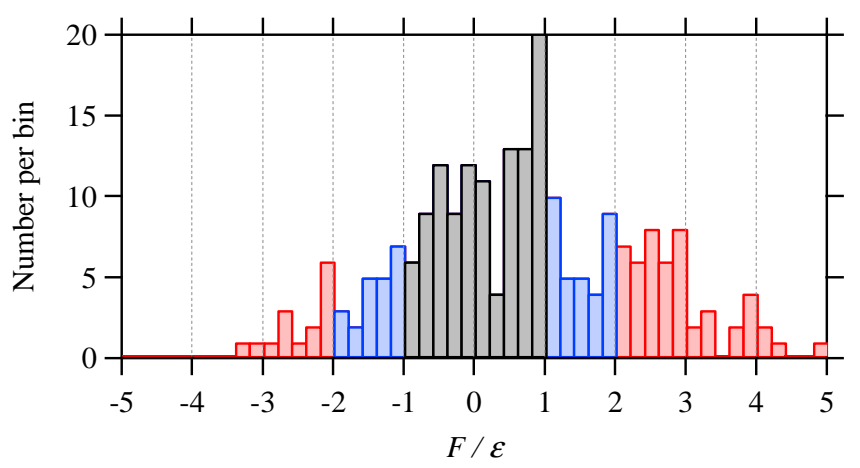

Fig. 6. Distribution of the ratio $F / \varepsilon$ for particles between 56.8 and $68.6 \mathrm{~nm}$. Blue and red bars show measurements which differ from 0 with a $68 \%$ confidence and red bars show measurements which differ from 0 with a $95 \%$ confidence.

measurements of $\mathrm{NO}_{3}^{-}$show a strong downward tendency, with $61 \%$ of fluxes with $F_{m}<-\varepsilon$ and $7 \%$ of fluxes with $F_{m}>\varepsilon$. 


\subsection{Inter-study comparison}

During the 2006 study, air temperatures were generally higher than during the 2009 study, with daily maxima ranging from $24^{\circ} \mathrm{C}$ to $37^{\circ} \mathrm{C}$ (2006), compared to daily maxima ranging from $20^{\circ} \mathrm{C}$ to $27^{\circ} \mathrm{C}$ (2009). The average daily mean temperature was $23^{\circ} \mathrm{C}$ during the 2006 study and $18^{\circ} \mathrm{C}$ during the 2009 study. Precipitation levels were similar during both years, with slightly more than $40 \mathrm{~mm}$ in the approximately 2 week duration of both studies. SMPS measurements in the 2006 study also demonstrate similar particle size growth episodes and similar size distributions when compared to the 2009 FMPS measurements. Both studies had $\mathrm{SO}_{2}$ concentrations above background levels for a similar fraction of time (between 12 and $15 \%$, depending on the background threshold value).

As discussed in Sect. 4.2, significant downward fluxes of $\mathrm{NO}_{3}^{-}$were observed in the 2006 study, which may relate to ammonium-nitrate evaporation. Lower temperatures during the 2009 study suggest that the relative contribution of $\mathrm{NO}_{3}^{-}$ to the aerosol mass would be larger. Further, the hotter temperatures in 2006 would likely be associated with stronger temperature gradients, which may affect ammonium-nitrate evaporation. These possibilities are discussed in the following sections.

\subsection{Net storage and source fluxes}

Following Rannik et al. (2009), we calculate the storage flux as

$$
F_{\mathrm{Stg}}=z_{r} \frac{C^{+}(t+T)-C^{+}(t)}{T}
$$

where $z_{r}=33 \mathrm{~m}, T=1800 \mathrm{~s}$, and $C^{+}(t)$ and $C^{+}(t+T)$ are the 120-s averages at the start and end of each 30-min period. This assumes a constant concentration with height. This is supported by a comparison of the 2-m and 33-m FMPS measurements, since the average difference between the 2-m and $33-\mathrm{m}$ particle number concentrations in the $62 \mathrm{~nm}$ size bin was relatively small ( $3 \%)$. The results show weak sensitivity to the averaging time, with very little difference in the calculated storage fluxes using averaging times of $30 \mathrm{~s}$ and $300 \mathrm{~s}$ in Eq. (10).

The average values $\langle F\rangle$ and $\left\langle F_{\text {Stg }}\right\rangle$ are compared in Fig. 7 (black and blue lines, respectively). For a very long, periodic time series the average $\left\langle F_{\mathrm{Stg}}\right\rangle$ should be negligible. Here, we see a negative storage flux for $D<60 \mathrm{~nm}$, and a small positive storage flux for $60<D<250 \mathrm{~nm}$. When unfiltered data is used $(n=736)$, the storage flux is much smaller $\left(\left|F_{\text {Stg }}\right|<0.08 \times 10^{6} \mathrm{~m}^{-2} \mathrm{~s}^{-1}\right.$ for all sizes). This suggests a bias in the filtered data towards a decreasing concentration of small particles $(D<60 \mathrm{~nm})$, and an increasing concentration of mid-range particles $(60<D<250 \mathrm{~nm})$. The average values of the total source $\left(\left\langle S_{T}\right\rangle=\left\langle F_{\mathrm{Stg}}\right\rangle+\langle F\rangle\right)$ are shown in

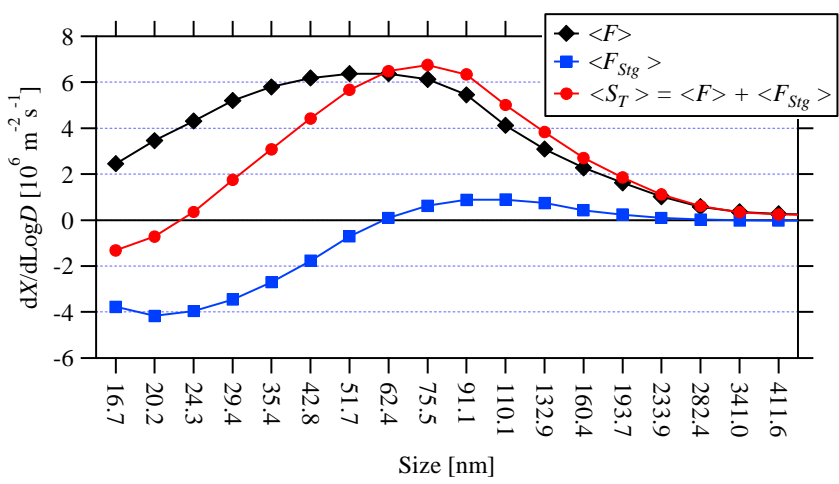

Fig. 7. Fluxes and storage rates by bin midpoint size $(D)$. The variable $X$ in $d X / d \log D$ represents average flux, $\langle F\rangle$, storage rate, $\left\langle F_{\text {Stg }}\right\rangle$, or source rate, $\left\langle S_{T}\right\rangle$, as described in the legend.

Fig. 7 (red line). The fraction of $S_{T}$ that is upward is $57 \%$, which is a small change from the $60 \%$ fraction of $F$ that is upward.

\section{Discussion}

This discussion focuses on the apparent upward fluxes of the 2009 study. These upward fluxes occur with significantly greater frequency than in previous studies over forest locations (see Sect. 1). As shown in Sect. 4.3, these upward fluxes are not associated with random, stochastic error, and remain even after filtering and corrections are applied. Pryor et al. (2008a) investigated the effect of wind direction, assuming a point or line source of emissions, and the angle of attack on the sonic anemometer, which has been shown to give erroneous flux measurements. An investigation (not shown here) of fluxes sorted by wind direction and sonic angle of attack (as determined by the second sonic rotation angle) shows no correlation between flux direction and either variable $\left(r^{2}<0.01\right)$. Hence the fluxes appear to indicate a net source of particles at or below the canopy. Below we investigate the influence of various effects on the upward particle fluxes.

\subsection{Ammonium-nitrate evaporation}

As discussed in Sect. 4.2, a vertical temperature gradient can lead to a relative change in the equilibrium of $\mathrm{NH}_{4} \mathrm{NO}_{3}$ in particles and $\mathrm{NH}_{3}$ and $\mathrm{HNO}_{3}$ gases in the atmosphere. Since the equilibrium is also affected by relative humidity, a change in $S_{R}$ with height will have the same effect. This change in equilibrium with height can cause a vertical gradient in particle size, due to the evaporation of $\mathrm{NH}_{4} \mathrm{NO}_{3}$ from particles. For a size-resolved instrument such as the FMPS, the vertical gradient of particle size results in a false flux, which is similar to the false fluxes caused by the deliquescence effect discussed in Sect. 3.1. 
Nemitz and Sutton (2004) modelled the effect of $\mathrm{NH}_{4} \mathrm{NO}_{3}$ evaporation on the apparent deposition velocity and found that, for some scenarios, the evaporation can lead to apparent emission of small particles. In one scenario, false positive fluxes were seen for particles less than $300 \mathrm{~nm}$ at a height of $10 \mathrm{~m}$. Here, we investigation the extent of false fluxes due to ammonium-nitrate evaporation. The equilibrium mass concentration of $\mathrm{NH}_{4} \mathrm{NO}_{3}, M$, is a function of temperature, $T$, and relative humidity, $S_{R}$, as well as the concentrations of $\mathrm{NH}_{4} \mathrm{NO}_{3}, \mathrm{NH}_{3}$, and $\mathrm{HNO}_{3}$, (cf. Mozurekwich, 1993; Nemitz and Sutton, 2004). Assuming all aerosol particles contain some $\mathrm{NH}_{4} \mathrm{NO}_{3}$, the change in mass of particles (with diameter $D$ ) due to the evaporation or condensation of $\mathrm{NH}_{4} \mathrm{NO}_{3}$ is

$d M=C(D) \rho_{\mathrm{AN}} \pi D^{2} d D$,

where $\rho_{\mathrm{AN}}$ is the density of $\mathrm{NH}_{4} \mathrm{NO}_{3}$ in the particle. For an incremental change in particle mass due to a change in temperature

$d M=\frac{\partial M}{\partial T} d T$.

From Eqs. (11) and (12),

$\frac{d D}{d T}=\frac{1}{C(D) \rho_{\mathrm{AN}} \pi D^{2}} \frac{\partial M}{\partial T}$.

Following the derivation of the deliquescence correction discussed in Sect. 3.1, the deposition velocity correction due to a change in particle diameter is

$\Delta V_{\mathrm{d}}=\beta \overline{w^{\prime} \frac{D^{\prime}}{D}}$,

with $\beta$ from Eq. (6). The first order Taylor polynomial approximation $\left(D^{\prime}=\frac{d D}{d T} T^{\prime}\right)$ can then be used to combine Eqs. (13) and (14) to give a deposition velocity correction as a function of the heat flux. These steps (Eqs. 12 through 14) can be repeated with $S_{R}$ in lieu of $T$, and the corrections can be summed to give

$$
\begin{aligned}
\Delta F(D) & =-\Delta V_{\mathrm{d}} C(D) \\
& =\frac{-\beta}{\rho_{\mathrm{AN}} \pi D^{3}}\left(\frac{\partial M}{\partial T} \overline{w^{\prime} T^{\prime}}+\frac{\partial M}{\partial S_{R}} \overline{w^{\prime} S_{R}^{\prime}}\right) .
\end{aligned}
$$

Although the changes in mass due to temperature $(\partial M / \partial T)$ and relative humidity $\left(\partial M / \partial S_{R}\right)$ are not known, they are both negative (Mozurkewich, 1993), since an increase in $T$ or $S_{R}$ will lead to increased evaporation of $\mathrm{NH}_{4} \mathrm{NO}_{3}$ from the particles and a reduction in particle size according to Eq. (13). Heat and moisture fluxes are both generally positive throughout the day. Hence, the sign of the flux correction is determined by the sign of $\beta$. Figure 8 shows $\beta$ with diameter $D$, calculated from Eq. (6) using the median size distribution shown in Fig. 2. Although it is not possible to model the magnitude of the correction without further knowledge of

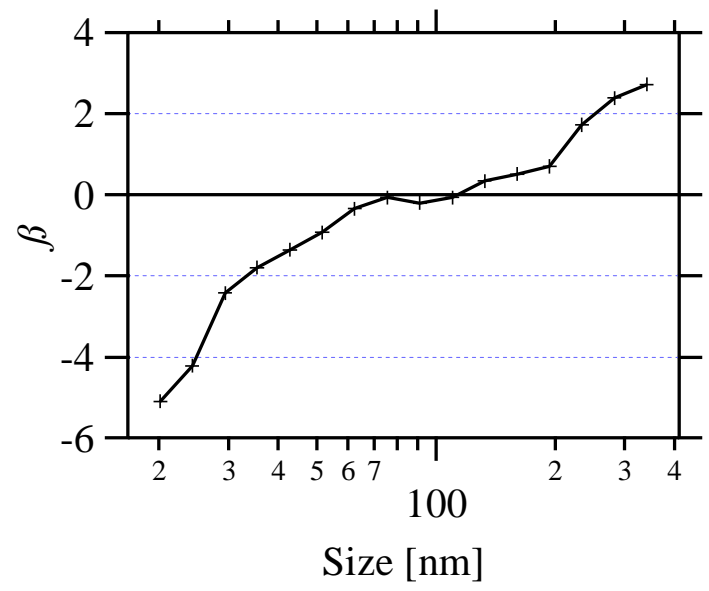

Fig. 8. The distribution of $\beta$ (Eq. 6) with size, $D$, determined using the median size distribution shown in Fig. 2.

particulate and gas concentrations, this demonstrates a negative flux correction is necessary for sizes below $70 \mathrm{~nm}$ and a positive flux correction is necessary for sizes above $130 \mathrm{~nm}$. Figure 4 demonstrates that the apparent fluxes are generally positive for the range $16.7<D<410 \mathrm{~nm}$, with a peak near $62 \mathrm{~nm}$.

Although an ammonium-nitrate evaporation correction would likely result in negative corrected fluxes for $D<$ $70 \mathrm{~nm}$, the correction would not significantly change fluxes in the $70<D<130 \mathrm{~nm}$ range, and it would increase upward fluxes for sizes above $D>130 \mathrm{~nm}$. It has been shown that $\mathrm{NH}_{4} \mathrm{NO}_{3}$ evaporation can also be driven by a decrease in $\mathrm{HNO}_{3}$ and $\mathrm{NH}_{3}$ near the ground due to vegetation uptake (Ryder, 2010). Although this is neglected by the above analysis, it would lead to increased evaporation below the measurement point, which would have the same effect as a positive heat or moisture flux and the direction of the flux correction would not be affected. Based on these results, it is possible that ammonium-nitrate evaporation may explain the upward fluxes at lower particle sizes $(D<70 \mathrm{~nm})$, however, upward fluxes in the larger particle sizes $(D>130 \mathrm{~nm})$ are not likely explained by this effect.

\subsection{Effect of precipitation}

Precipitation was measured in 15-min intervals at a nearby pond ( $280 \mathrm{~m} \mathrm{NE}$ of the tower). In addition to these measurements, leaf wetness was measured at a height of $33 \mathrm{~m}$. Leaf wetness is defined as either dry or wet based on a calibrated sensor resistance. Daily precipitation values were also measured at the Egbert station (Climate ID 611E001), which is located $15 \mathrm{~km} \mathrm{SE}$ of the tower. These three measurements were used to distinguish dry conditions from wet conditions, with wet conditions defined as either non-zero 15-min precipitation, a wet leaf reading, or a day with measured precipitation of more than $4 \mathrm{~mm}$. Table 1 compares the fluxes 
for the $62 \mathrm{~nm}$ bin for wet and dry conditions. Fluxes are significantly higher when conditions are dry, for all three precipitation criteria. The largest difference is seen when the leaf wetness criterion is used; however, this may be due to morning condensation, when fluxes were generally lower. A similar difference is also seen using the criterion of daily precipitation, which does not include a diurnal effect since the whole day is classified as either wet or dry. The difference in fluxes between wet and dry conditions is smaller for the 15-min precipitation criterion; however, there were a small number of flux measurements during rain. When the 15-min precipitation measurements are converted to daily totals and the criterion of daily precipitation $>4 \mathrm{~mm}$ is used, the difference between fluxes on dry days and wet days is more pronounced, with significantly more upward fluxes on dry days. Hence there is an apparent link between the absence of precipitation and upward fluxes. This could be due to increased deposition to wet surfaces, as was found by Erisman and Draaijers (2003). This could also relate to the evaporation of $\mathrm{NH}_{4} \mathrm{NO}_{3}$, since precipitation will result in a weak temperature gradient, which will suppress $\mathrm{NH}_{4} \mathrm{NO}_{3}$ evaporation relative to dry and sunny days; however insufficient information is available from these measurements to allow for more than speculation.

\subsection{Mixing}

Ahlm et al. (2009) measured particle fluxes for $D>10 \mathrm{~nm}$ above the Amazon rain forest. They found that the median fraction of upward fluxes (over a 9 week period) varied from 30 to $55 \%$ through the night and morning, then briefly peaked above $70 \%$ before midday, after which it remained between 20 and 50\% (their Fig. 10). Nilsson et al. (2001) examined particle flux data from a pine forest in Hyytiälä, Finland. They showed results for a single day (their Fig. 9), during which fluxes were downward, between 0 and $-10^{7} \mathrm{~m}^{-2} \mathrm{~s}^{-1}$ through the night and into the early morning. A few hours after sunrise, the flux briefly peaked above $5 \times 10^{6} \mathrm{~m}^{-2} \mathrm{~s}^{-1}$ (upward), after which it dropped to between $-15 \times 10^{6} \mathrm{~m}^{-2} \mathrm{~s}^{-1}$ and $-80 \times 10^{6} \mathrm{~m}^{-2} \mathrm{~s}^{-1}$ (downward) for the remainder of the day.

The brief morning peak upward flux was ascribed in both cases to the growth of the mixing layer as it passed the measurement point. This would entrain cleaner air from above, resulting in a positive flux measurement. From Eq. (3), this implies a negative storage rate, $F_{\text {Stg }}$ caused by the dilution of particles out of the forest, which is balanced by positive flux, $F$ (assuming the source term $S_{T}$ does not change significantly during this period). Figure 9 shows the fraction of upward fluxes for $18<D<452 \mathrm{~nm}$ sorted by hour of day during the present study. Here, there is no brief peak between sunrise (10:00 UTC) and midday. The fraction of upward fluxes varied from 20 to $80 \%$ throughout the night, then steadily climbed throughout the day after 12:00 UTC, reaching a maximum after 17:00. The diurnal fraction for

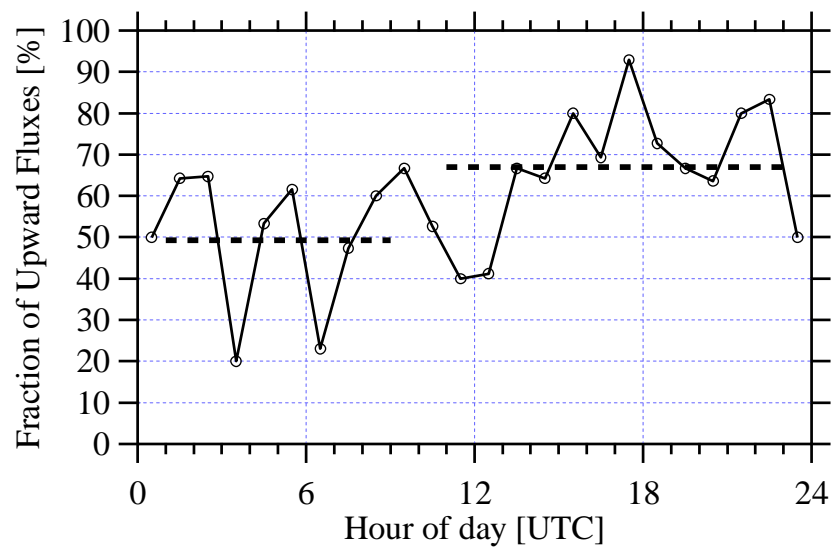

Fig. 9. Fraction of upward fluxes by hour of day for $18<D<$ $452 \mathrm{~nm}$. Average values for night (01:00-09:00) and day (11:0023:00) also shown (dashed lines).

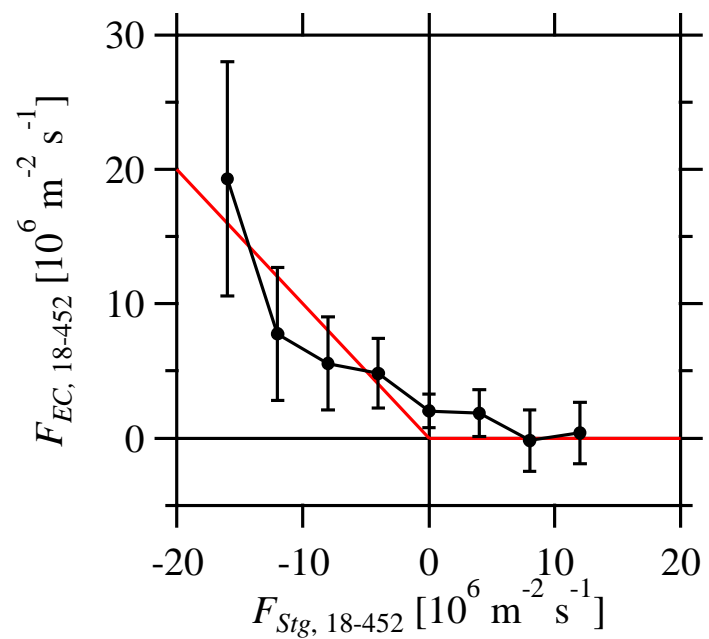

Fig. 10. Average eddy covariance fluxes binned by storage flux for $18.4-452 \mathrm{~nm}$ particles. Error bars show the $95 \%$ confidence interval.

the $62 \mathrm{~nm}$ bin fluxes (not shown) followed a similar pattern, as does the diurnal fraction without the filtering of fluxes for low friction velocities $\left(u_{*}<0.2 \mathrm{~m} \mathrm{~s}^{-1}\right)$.

To investigate the relation between flux and storage flux, the eddy covariance fluxes for $18<D<452 \mathrm{~nm}$ are sorted by storage flux and averaged, as shown in Fig. 10. A comparison was also made (not shown) for fluxes from the $62 \mathrm{~nm}$ bin, and analysis for both size ranges was repeated without the filtering of fluxes for low friction velocities $\left(u_{*}<\right.$ $0.2 \mathrm{~m} \mathrm{~s}^{-1}$ ). The average values determined by all four methods gave a similar pattern to the filtered, total flux shown in Fig. 10. This pattern can be modelled as

$$
F=\left\{\begin{array}{r}
-F_{\mathrm{Stg}}, F_{\mathrm{Stg}}<0 \\
0, F_{\mathrm{Stg}}>0
\end{array}\right.
$$


Table 1. Quartiles of $62 \mathrm{~nm}$ bin fluxes $\left[10^{6} \mathrm{~m}^{-2} \mathrm{~s}^{-1}\right]$ and number of observations, $n$, for wet and dry conditions as determined by various measurement types.

\begin{tabular}{lrrrr|rrrr}
\hline Measurement & \multicolumn{3}{c}{ Wet } & \multicolumn{5}{c}{ Dry } \\
& 25th & Median & 75th & $n$ & 25th & Median & 75th & $n$ \\
\hline 15-min Precip (Pond) & -0.18 & 0.031 & 0.23 & 30 & -0.11 & 0.077 & 0.55 & 328 \\
Leaf Wetness & -0.16 & 0.021 & 0.25 & 120 & -0.07 & 0.111 & 0.68 & 238 \\
Daily Obs. (Egbert) & -0.20 & 0.026 & 0.31 & 153 & -0.05 & 0.109 & 0.65 & 205 \\
Daily Obs. (Pond) & -0.18 & 0.026 & 0.26 & 143 & -0.06 & 0.126 & 0.66 & 215 \\
\hline
\end{tabular}

Despite this pattern, the correlation between the measured values of $F$ and those determined by Eq. (16) is very low $\left(r^{2}=0.05\right)$, probably owing to the large amount of scatter in the data, and nearly $9 \%$ of the data are outside of the range $\left(-18 \times 10^{6}<F_{\text {Stg }}<18 \times 10^{6} \mathrm{~m}^{-2} \mathrm{~s}^{-1}\right)$ shown in the figure. However, this simple model generally supports the conclusions of Nilsson et al. (2001) and Pryor et al. (2008a), who suggested that observed upward fluxes are due to the entrainment of particle-depleted, chemically-aged air from the free troposphere, which would result in a decrease in concentration (negative storage flux). This is also supported by a comparison of the median fluxes during decreasing mean diameter $\left(F_{18-452}=1.3 \times 10^{6} \mathrm{~m}^{-2} \mathrm{~s}^{-1}\right)$ and increasing mean diameter $\left(F_{18-452}=2.3 \times 10^{6} \mathrm{~m}^{-2} \mathrm{~s}^{-1}\right)$, since the mixing of chemically-aged air from above should result in an increasing mean diameter, which is associated with a higher upward flux. If it is assumed that Eq. (16) holds over a long-term average, this gives a source term (from Eq. 3) of $S_{T}=0$ during a negative storage rate, and $S_{T}=F_{\text {Stg }}$ during a positive storage rate. This implies that, over the long-term, the observed upward fluxes are not an immediate result of particle formation and growth. Instead, particles within or below the canopy are stored and then later diluted out into the cleaner air above, which results in an observed upward flux. However, this process appears to apply only over a long-term average, since the correlation between measured $F_{\text {Stg }}$ and modelled $F_{\text {Stg }}$ (from Eq. 16 ) is very low.

\subsection{Day-to-day variation}

Although there appears to be a relationship between upward fluxes and negative storage, there is a large amount of scatter in the data and a poor agreement between Eq. (16) and the measurements. This suggests that the model works well on average, but there is a large amount of variation between different days. Below we investigate the evolution of the fluxes and changes in concentration (storage flux) to see how they interact on a day by day basis.
Figure 11 compares the flux (blue line) and concentration (black line) for the $62 \mathrm{~nm}$ bin $(56.8-68.6 \mathrm{~nm})$ between 15 July and 2 August. Fluxes from times which would normally be filtered for wind direction or low friction velocities are shown (light blue line) for qualitative comparison. Generally, filtered night-time fluxes (shaded regions) were small, and daytime fluxes were positive, as demonstrated in Sect. 4.1. On DOY 196, two strong increases in concentration (positive storage flux) early and late in the day coincided with downward fluxes. However, between these two increases, fluxes were strongly upward. DOY 202 and 203 were both characterized by a storage of particles through the night, followed by a decrease in concentration (negative storage flux) in the morning, and generally upward fluxes throughout the day. DOY 206 and 212 were similar to DOY 202 and 203, with generally upward fluxes, although the decrease in concentration was delayed until mid-day, and in DOY 212, there was no storage of particles at night (and very few valid flux measurements). Hence, there generally appears to be a correlation between decreasing concentration (negative storage flux) and upward fluxes during the day. DOY 207 and 213 provide an interesting corollary, as fluxes were nearly zero or downward during both days, and the concentrations were continually increasing (DOY 207) or increasing and then nearly constant (DOY 213) throughout the day.

\subsection{Decoupling of the canopy space}

Measurements of the $62 \mathrm{~nm}$ bin concentration at $2 \mathrm{~m}$ are also shown (red line) in Fig. 11. At some points, there was a lag between the $33 \mathrm{~m}$ and $2 \mathrm{~m}$ time series. This lag was present through the night and in the morning, but disappeared each day during particle growth near peak daylight, as is demonstrated by the coincident peaks near mid-day. It was present during both concentration increase (positive storage flux) and decrease (negative storage flux). Figure 12 shows the diurnal cycle of the lag, with positive lag indicating that the 2-m signal was delayed relative to the 33-m signal. The lag averages approximately $2 \mathrm{~h}$ through the night and reaches zero at mid-day. 

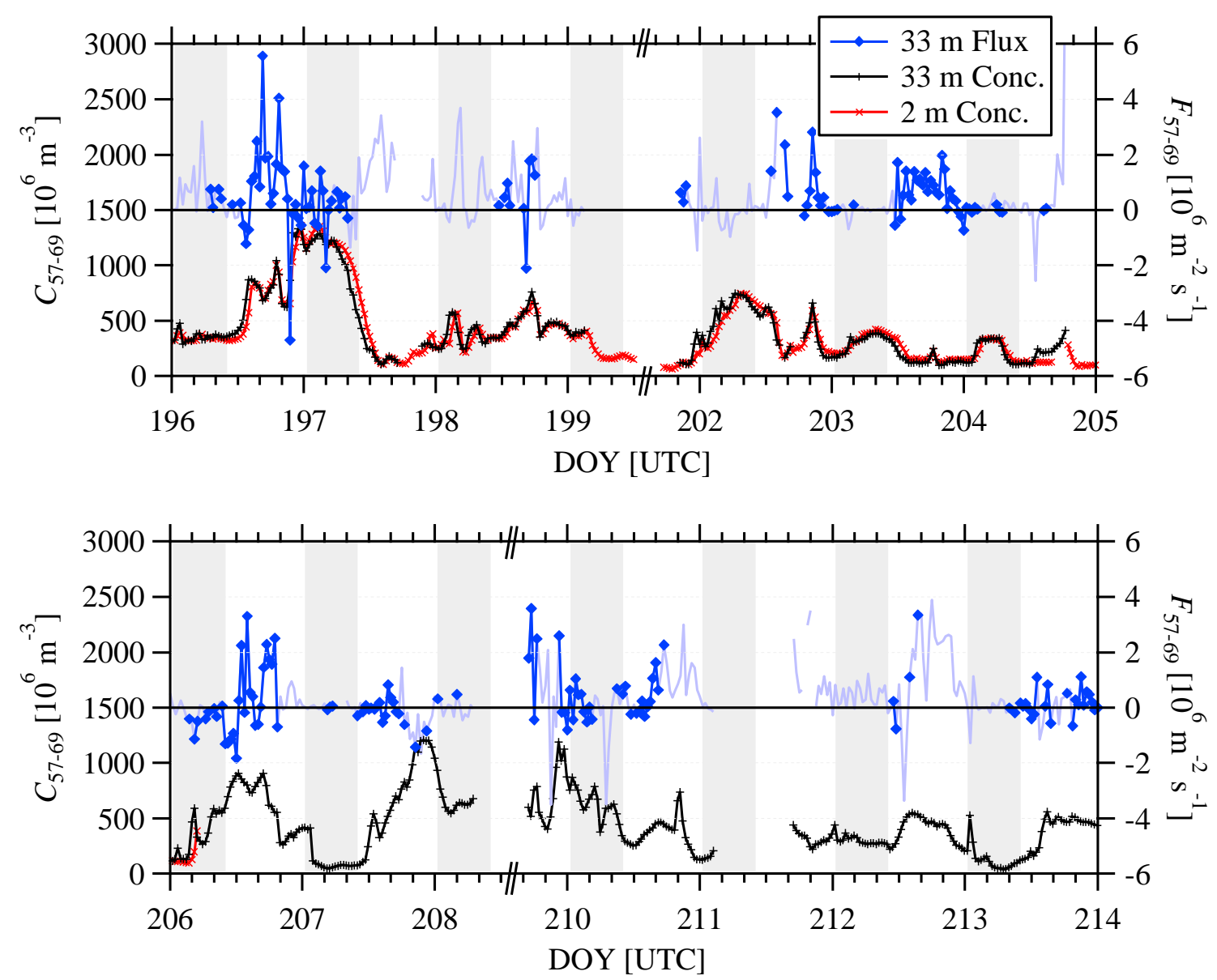

Fig. 11. Concentrations ( $33 \mathrm{~m}$ and $2 \mathrm{~m}$ ) and fluxes $(33 \mathrm{~m})$ for $56.8-68.6 \mathrm{~nm}$ particles. The light blue line shows fluxes which were removed from analysis due to wind direction or low friction velocities. Nights are shaded.

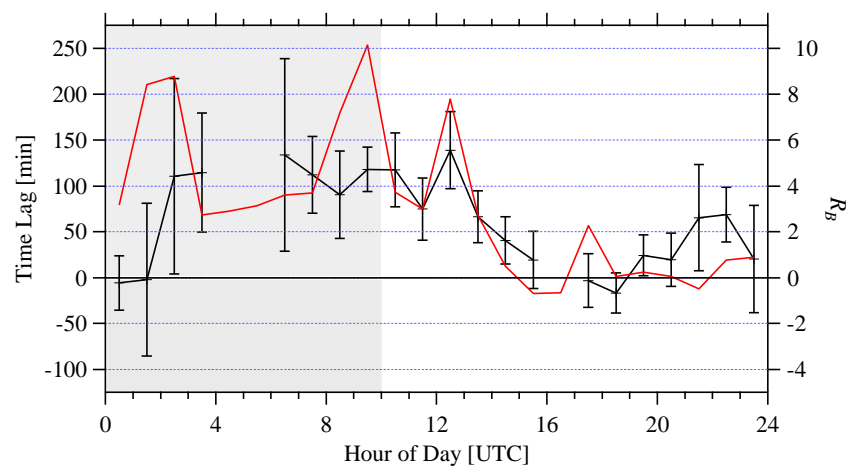

Fig. 12. Average time lag of 2-m concentration signal behind 33$\mathrm{m}$ signal (black line) sorted by hour of day. Error bars show $95 \%$ confidence interval. Average canopy Richardson number (Eq. 17) also shown (red line). Night is shaded.

Similar lag results are seen in the measurements of Whitehead et al. (2010). They compare sub-micron number concentration at a height of $33 \mathrm{~m}$ (in a $35 \mathrm{~m}$ canopy) to the sub- micron number concentration at $8 \mathrm{~m}$ and find that the changes in the $8 \mathrm{~m}$ concentration lag the $33 \mathrm{~m}$ concentration changes, with the delay following a diurnal cycle similar to Fig. 12. The median delays at night vary from 20 to $110 \mathrm{~min}$; similar to the 80 to $130 \mathrm{~min}$ average delays seen in this study.

These results suggests that particle number concentration changes in mid-canopy are translated to the forest floor very slowly at night (timescale $1-2 \mathrm{~h}$ ), while they are translated to above the canopy much faster. As particle laden or particle depleted air is transported above the forest, there may be delay in either mixing particles into or out of the canopy space. This is most likely to be the case during the night and in the early morning, when there is little turbulent mixing. The lag is compared in Fig. 12 to the canopy Richardson number (Mammarella et al., 2007), defined as:

$R_{B}=\frac{g z\left(\theta_{33 \mathrm{~m}}-\theta_{17 \mathrm{~m}}\right)}{\theta_{33 \mathrm{~m}} u_{33 \mathrm{~m}}^{2}}$,

where $g$ is the acceleration due to gravity, $\theta_{17 \mathrm{~m}}$ and $\theta_{33 \mathrm{~m}}$ are the potential temperatures at 17 and $33 \mathrm{~m}$ (below and above the canopy), and $u_{33 \mathrm{~m}}$ is the wind speed at $33 \mathrm{~m}$. The diurnal 
cycle of stability, as represented by $R_{B}$, is similar to the cycle of the time lag, suggesting that the time lag is associated with stability and mixing within the canopy. During the day, the time scales were roughly equal and particle concentration changes in mid-canopy were translated to the forest floor and to the $33 \mathrm{~m}$ level at approximately the same rate. This would explain why growing particles were stored in the canopy throughout the night without mixing out; whereas during the day, turbulent mixing time scales were much shorter and no lag between time series is seen.

To summarize the above discussion, the results suggest a growth of particles, which typically begins around mid-day. As these particles continued to grow in size and increase in number through the night, they tended to remain below the canopy due to the decreased mixing and longer timescales at night relative to the day. During this increasing number concentration (positive storage flux), fluxes were generally small (Fig. 10). During the day, when mixing increases and timescales were much smaller (Fig. 12), the negative storage flux (decreasing concentration) balanced the upward flux (Fig. 10). This results in the diurnal cycles of flux and flux direction which are shown in Figs. 3e and 9, respectively.

\section{Conclusions}

Flux measurements in the summer of 2009 demonstrate a significant amount of upward fluxes over this mixed forest location. The fraction of upward fluxes seen in this study $(60 \%)$ is higher than any previously reported fractions over forests, which range near $20 \%$ (Grönholm et al., 2007) to over $40 \%$ (Pryor et al., 2008c). The forest is a source of particles at this location with an average source rate of $3.1 \times 10^{6}$ particles $\mathrm{m}^{-2} \mathrm{~s}^{-1}$ for particles $18<D<452 \mathrm{~nm}$. This source rate is highest for sizes near $75 \mathrm{~nm}$. As there is no physical mechanism to create $75 \mathrm{~nm}$ particles, this suggests that the growth rate of the particles is slowest at $75 \mathrm{~nm}$, which would result in a higher source rate at that size.

Upward fluxes are associated with days without precipitation. During precipitation, reduced upward fluxes may be due to increased deposition to wet surfaces, less particle creation during wet days, or a reduction in ammonium-nitrate evaporation due to weaker temperature gradients.

Previous suggestions for upward fluxes included sources of particles within or close to the canopy top (Buzorius et al., 1998), or the entrainment of clean, particle depleted air from above (Pryor et al., 2008a). What is seen in this study combines both effects. Generally, there is an association between decreasing concentration (negative storage flux) and upward fluxes, while average fluxes are very small during increasing concentration (positive storage flux). Due to the decoupling of the above and below canopy spaces, particles are stored within the canopy, and then diluted through mixing with the chemically aged, cleaner air above. On average, this creates a positive flux during net depletion of particles from the forest.
Ammonium-nitrate evaporation could explain the apparent upward fluxes at small particle sizes. Chemically speciated flux measurements from a 2006 study at the same location suggest that there is no significant gradient of sulphate aerosol concentrations and there is a significant positive gradient (increasing with height) of nitrate concentration above the canopy, possibly enhanced by the evaporation of ammonium-nitrate at the canopy at sunrise. However, modelling of the sign of the associated flux correction suggests this effect would not explain the peak fluxes see above $60 \mathrm{~nm}$. Hence, it is difficult to know the extent of the false fluxes due to ammonium-nitrate evaporation and further research is required to quantify this effect.

Acknowledgements. This work was supported by the Natural Science and Engineering Research Council of Canada and was funded by the Science and Technology Branch, Environment Canada. The authors thank Alexandre Petroff for insight and suggestions; Greg Evans for the use of one FMPS; Jose-Luis Jimenez for his assistance with the AMS software; Patrick Lee and John Deary for general technical assistance; the Canadian Forces Base Borden for hosting the Flux Tower site; and the two anonymous reviewers, whose suggestions have improved the manuscript significantly.

Edited by: A. Laaksonen

\section{References}

Ahlm, L., Nilsson, E. D., Krejci, R., Mårtensson, E. M., Vogt, M., and Artaxo, P.: Aerosol number fluxes over the Amazon rain forest during the wet season, Atmos. Chem. Phys., 9, 9381-9400, doi:10.5194/acp-9-9381-2009, 2009.

Ahlm, L., Krejci, R., Nilsson, E. D., Mårtensson, E. M., Vogt, M., and Artaxo, P.: Emission and dry deposition of accumulation mode particles in the Amazon Basin, Atmos. Chem. Phys., 10, 10237-10253, doi:10.5194/acp-10-10237-2010, 2010.

Bleyl, M. R.: Experimentelle Bestimmung der Depositionsgeschwindigkeit luftgetragener Partikel mit Hilfe der Eddy - Kovarianzmethode über einem Fichtenaltbestand im Solling. PhD Thesis (in German), University of Göttingen, Göttingen, Germany, 2001.

Businger, J. A.: Evaluation of the accuracy with which dry deposition can be measured with current micrometeorological techniques, J. Clim. Appl. Meteorol., 25, 1100-1124, 1986.

Buzorius, G., Rannik, Ü., Mäkelä, J. M., Vesala, T., and Kulmala, M.: Vertical aerosol particle fluxes measured by eddy covariance technique using condensational particle counter, J. Aerosol. Sci., 29(1/2), 157-171, 1998.

Buzorius, G., Rannik, Ü., Mäkelä, J. M., Keronen, P., Vesala, T., and Kulmala, M.: Vertical aerosol fluxes measured by the eddy covariance method and deposition of nucleation mode particles above a Scots pine forest in southern Finland, J. Geophys. Res., 105 (D15), 19905-19916, 2000.

Crosier, J., Jimenez, J. L., Allan, J. D., Bower, K. N., Williams, P. I., Alfarra, R., Canagaratna, M. R., Jayne, J. T., Worsnop, D. R., and Coe, H.: Technical Note: Description and use of the New Jump Mass Spectrum Mode of Operation for the Aerodyne Quadrupole 
Aerosol Mass Spectrometer (QAMS), Aerosol Sci. Technol., 41, 865-872, 2007.

Erisman, J. W. and Draaijers, G.: Deposition to forests in Europe: most important factors influencing dry deposition and models used for generalisation, Environ. Pollut., 124(3), 379-388, 2003.

Forster, P., Ramaswamy, V., Artaxo, P., Berntsen, T., Betts, R., Fahey, D. W., Haywood, J., Lean, J., Lowe, D. C., Myhre, G., Nganga, J., Prinn, R., Raga, G., Schulz M., and Van Dorland, R.: Changes in Atmospheric Constituents and in Radiative Forcing, in: Climate Change 2007: The Physical Science Basis. Contribution of Working Group I to the Fourth Assessment Report of the Intergovernmental Panel on Climate Change, edited by: Solomon, S., Qin,, D. Manning, M., Chen, Z., Marquis, M., Averyt, K. B., Tignor, M., and Miller, H. L., Cambridge University Press, Cambridge, United Kingdom and New York, NY, USA, 2007.

Gallagher, M. W., Beswick, K. M., Duyzer, J., Westrate, H., Choulartron, T. W., and Hummelshøj, P.: Measurements of aerosol fluxes to Speulder forest using a micrometeorological technique, Atmos. Environ., 31(3), 359-373, 1997.

Gaman, A., Rannik, Ü., Aalto, P., Pohja, T., Siivola, E., Kulmala, M., and Vesala, T.: Relaxed eddy accumulation system for sizeresolved aerosol particle flux measurements, J. Atmos. Ocean. Tech., 21, 933-943, 2004.

Grönholm, T., Aalto, P. P., Hiltunen, V., Rannik, Ü., Rinne, J., Laakso, L., Hyvönen, S., Vesala, T., and Kulmala, M.: Measurements of aerosol particle dry deposition velocity using the relaxed eddy accumulation technique, Tellus B, 59, 381-386, 2007.

Held, A. and Klemm, O.: Direct measurement of turbulent particle exchange with a twin CPC eddy covariance system, Atmos. Environ., 40, 92-102, doi:10.1016/j.atmosenv.2005.09.092, 2006.

Hicks, B. B., Matt, D. R., McMillen, R. T., and Womack, J. D.: A field investigation of sulfate fluxes to a deciduous forest, $\mathrm{J}$. Geophys. Res., 94(10) 13003-13011, 1989.

Horst, T. W.: A simple formula for attenuation of eddy fluxes measured with first-order-response scalar sensors, Bound.-Lay. Meteorol., 82, 219-233, 1997.

Jimenez, J. L., Jayn,e J. T., Shi, Q., Kolb, C. E., Worsnop, D. R., Yourshaw, I., Seinfeld, J. H., Flagan, R. C., Zhang, X., Smith, K. A., Morris, J. W., and Davidovits, P.: Ambient aerosol sampling using the Aerodyne Aerosol Mass Spectrometer, J. Geophys. Res., 108(D7), 8425-8438, doi:10.1029/2001JD001213, 2003.

Kowalski, A.: Deliquescence induces eddy covariance and estimable dry deposition errors, Atmos. Environ., 35, 4843-4851, 2001.

Lamaud, E., Brunet, Y., Labatut, A., Lopez, A., Fontan, J., and Druilhet, A.: The Landes experiment: biosphere-atmosphere exchanges of ozone and aerosol particles above a pine forest, J. Geophys. Res., 99, 16511-16521, 1994.

Lee, X. H., Fuentes, J. D., Staebler, R. M., and Neumann, H. H.: Long-term observation of the atmospheric exchange of $\mathrm{CO}_{2}$ with a temperate deciduous forest in southern Ontario, Canada, J. Geophys. Res.-Atmos., 104(D13), 15975-15984, 1999.

Lumley, J. L. and Panofsky, H. A.: The Structure of Atmospheric Turbulence, Wiley Interscience, New York, 1964.

Malm, W. C.: Fundamentals of visibility, in: Handbook of Weather, Climate and Water: Atmospheric Chemistry, Hydrology, and So- cietal Impacts, edited by: Potter, D. T. and Colman, B. R., 285329, John Wiley, Hoboken, N.J., 2003.

Mammarella, I., Kolari, P., Rinne, J., Keronen, P., Pumpanen, J., and Vesala, T.: Determining the contribution of vertical advection to the net ecosystem exchange at Hyytiälä forest, Finland, Tellus B, 59, 900-909, 2007

Mozurkewich, M.: The dissociation constant of ammonium nitrate and its dependence on temperature, relative humidity and particle size, Atmos. Environ., 27, 261-270, 1993.

Nemitz, E. and Sutton, M. A.: Gas-particle interactions above a Dutch heathland: III. Modelling the influence of the $\mathrm{NH}_{3}$ $\mathrm{HNO}_{3}-\mathrm{NH}_{4} \mathrm{NO}_{3}$ equilibrium on size-segregated particle fluxes, Atmos. Chem. Phys., 4, 1025-1045, doi:10.5194/acp-4-10252004, 2004.

Nemitz, E., Jimenez, J. L., Huffman, A., Ulbrich, I. M., Canagaratna, M. R., Worsnop, D. R., and Guenther, A. B.: An EddyCovariance System for the Measurement of Surface/Atmosphere Exchange Fluxes of Submicron Aerosol Chemical Species - First Application Above an Urban Area, Aerosol Sci. Tech., 42, 636657, 2008.

Nilsson, E. D., Rannik, Ü., Kulmala, M., Buzorius, G., and O'Dowd, C. D.: Effects of continental boundary layer evolution, convection, Tellus B, 53, 441-461, 2001.

Petroff, A., Mailliat, A., Amielh, M., and Anselmet, F.: Aerosol dry deposition on vegetative canopies. Part I: Review of present knowledge, Atmos. Environ., 42(16), 3625-3653, doi:10.1016/j.atmosenv.2007.09.043, 2008.

Pryor, S. C.: Size resolved particle deposition velocities of sub$100 \mathrm{~nm}$ diameter particles over a forest, Atmos. Environ., 40, 6192-6200, 2006.

Pryor, S. C., Larsen, S. E., Sørensen, L. L., Barthelmie, R. J., Grönholm, T., Kulmala, M., Launiainen, S., Rannik, Ü., and Vesala, T.: Particle fluxes over forests: Analyses of flux methods and functional dependencies, J. Geophys. Res., 112, D07205, doi:10.1029/2006JD008066, 2007.

Pryor, S. C., Barthelmie, R. J., Sørensen, L. L., Larsen, S. E., Sempreviva, A. M., Grönholm, T., Rannik, Ü., Kulmala, M., and Vesala, T.: Upward fluxes of particles over forests: when, where, why?, Tellus B, 60, 372-380, 2008a.

Pryor, S. C., Gallagher, M., Sievering, H., Larsen, S. E., Barthelmie, R. J., Birsan, F., Nemitz, E., Rinne, J., Kulmala, M., Grönholm, T., Taipale, R., and Vesala, T.: A review of measurement and modelling results of particle atmosphere - surface exchange, Tellus B, 60, 42-75, 2008b.

Pryor, S. C., Larsen, S. E., Sørensen, L. L., and Barthelmie, R. J.: Particle fluxes above forests: Observations, methodological considerations and method comparisons, Environ. Pollut., 152, 667-678, doi:10.1016/j.envpol.2007.06.068, 2008c.

Pryor, S. C., Barthelmie, R. J., Spaulding, A. M., Larsen, S. E., and Petroff, A.: Size-resolved fluxes of sub-100nm particles over forests, J. Geophys. Res., 114, D18212, doi:10.1029/2009JD012248, 2009.

Rannik, Ü., Vesala, T., and Keskinen, R.: On the dampening of temperature fluctuations in a circular tube relevant to eddy covariance measurement technique, J. Geophys. Res., 102(D11), 12789-12794, 1997.

Rannik, Ü., Mammarella, I., Aalto, P., Keronen, P., Vesala, T., and Kulmala, M.: Long-term aerosol particle flux observations part I: Uncertainties and time-average statistics, Atmos. Env- 
iron., 43(21), 3431-3439, doi:10.1016/j.atmosenv.2009.02.049, 2009.

Ryder, J.: Emission, deposition and chemical conversion of atmospheric trace substances in and above vegetation canopies, $\mathrm{PhD}$ Thesis, University of Manchester, UK, 241 pp, 2010.

Spranger, T., Lorenz, U., Gregor, H. D. (Eds.): Manual on methodologies and criteria for Modelling and Mapping Critical Loads \& Levels and Air Pollution Effects, Risks and Trends, Federal Environment Agency, Berlin, 2004.

Staebler, R. M., Fuentes, J. D., Lee, X. H., Puckett, K. J., Neumann, H. H., Deary, M. J., and Arnold, J. A.: Long term flux measurements at the Borden forest, CMOS Bull. SCMO, 28 (1), 9-16, 2000.

Swietlicki, E., Zhou, J., Covert, D. S., Hameri, K., Busch, B., and 11 others: Hygroscopic properties of aerosol particles in the northeastern Atlantic during ACE-2, Tellus B, 52, 201-227, 2000.

Teklemariam, T., Staebler, R. M., and Barr, A. G.: Eight years of carbon dioxide exchange above a mixed forest at Borden, Ontario, Agr. Forest Meteorol., 149, 2040-2053, doi:10.1016/j.agrformet.2009.07.011, 2009.

Tammet, H., Murmee, A., and Tamm, E.: Electrical aerosol spectrometer of Tartu University, Atmos. Res., 62, 315-3-24, doi:10.1016/S0169-8095(02)00017-0, 2002.
Thomas, R. M.: Measurement of Speciated Aerosol Fluxes. PhD Thesis, University of Manchester, Manchester, UK, 2007.

Vong, R. J., Vickers, D., and Covert, D. S.: Eddy correlation measurements of aerosol deposition to grass, Tellus B, 56, 105-117, 2004.

Webb, E., Pearman, G., and Leuning, R.: Correction of flux measurements for density effects due to heat and water vapour transfer, Q. J. Roy. Meteor. Soc., 106, 85-100, 1980.

Whitehead, J. D., Gallagher, M. W., Dorsey, J. R., Robinson, N., Gabey, A. M., Coe, H., McFiggans, G., Flynn, M. J., Ryder, J., Nemitz, E., and Davies, F.: Aerosol fluxes and dynamics within and above a tropical rainforest in South-East Asia, Atmos. Chem. Phys., 10, 9369-9382, doi:10.5194/acp-10-9369-2010, 2010.

Wilczak, J. M., Oncley, S. P., and Stage, S.A.: Sonic anemometer tilt correction algorithms, Bound.-Lay. Meteorol., 99, 127-150, 2001.

Wyers, G. P. and Duyzer, J. H.: Micrometeorological measurements of the dry deposition flux of sulphate and nitrate aerosols to coniferous forest, Atmos. Environ. 31(3), 333-343, 1997. 